\title{
Long term prognostic implication of newly detected abnormal glucose tolerance among patients with stable cardiovascular disease: a population- based study
}

Maryam Kabootari

Shaheed Beheshti University of Medical Sciences

Samaneh Asgari

Shaheed Beheshti University of Medical Sciences

Seyedeh Maryam Ghavam

Shaheed Beheshti University of Medical Sciences

Fereidoun Azizi

Shaheed Beheshti University of Medical Sciences

Farzad Hadaegh (D Fzhadaegh@endocrine.ac.ir)

Shaheed Beheshti University of Medical Sciences https://orcid.org/0000-0002-8935-2744

Original investigation

Keywords: impaired fasting glucose, impaired glucose tolerance, newly diagnosed diabetes, cardiovascular disease

Posted Date: April 14th, 2020

DOI: https://doi.org/10.21203/rs.3.rs-21088/v1

License: (c) (i) This work is licensed under a Creative Commons Attribution 4.0 International License. Read Full License

Version of Record: A version of this preprint was published at Journal of Translational Medicine on June 30th, 2021. See the published version at https://doi.org/10.1186/s12967-021-02950-y. 


\section{Abstract}

Background: To assess the association between fasting plasma glucose (FPG) and 2-h post challenge plasma glucose (2h-PCPG) as continuous or categorical variables with risk of recurrent cardiovascular disease (CVD) and incident diabetes among subjects with history of previous CVD.

Methods: In a prospective population-based cohort, a total of 335 Iranians aged $\geq 30$ years, with history of CVD and free of known diabetes were included. Prediabetes was defined as impaired fasting glucose (IFG) according to the criteria of the American Diabetes Association (ADA) [IFG-ADA; FPG: 5.6-6.9 $\mathrm{mmol} / \mathrm{L}$ ], the World Health Organization (WHO) expert group (IFG-WHO; FPG: 6.1-6.9 mmol/L) and impaired glucose tolerance [IGT: 2h-PCPG: 7.8-11.0 $\mathrm{mmol} / \mathrm{L}]$. Cox's proportional hazard models adjusted for traditional risk factors were used to estimate the hazard ratio (HR) with $95 \%$ confidence interval (Cl) of different glucose intolerance for outcomes of interest.

Results: During a median follow-up of 15.8 (IQR, 10.7-16.5) years, 178 CVD (hard event including death, myocardial infarction and stroke=69) events occurred. Regarding FPG, only IFG-ADA was associated with significant higher risk of hard CVD in the fully adjusted model (HR, 1.73, 95\% Cl: 1.04-2.89). Moreover, newly diagnosed diabetes (FPG $\geq 7 \mathrm{mmol} / \mathrm{L}$ ) was an independent risk of CVD (2.11: 1.22-3.66). Focusing on $2 \mathrm{~h}-\mathrm{PCPG}$, subjects with newly diagnosed diabetes ( $2 \mathrm{~h}-\mathrm{PCPG} \geq 11.1 \mathrm{mmol} / \mathrm{L})$ had moderately increased risk of hard coronary heart disease $(2.02: 0.91-4.47, \mathrm{P}=0.08)$. The multivariate $\mathrm{HRs}(95 \% \mathrm{Cl})$ associated with 1 SD increase in FPG and 2h-PCPG was 1.16 (1.01-1.33) and 1.19 (1.02-1.38) for CVD, respectively. Among population free of diabetes at baseline $(\mathrm{n}=270)$, IFG-ADA, IFG-WHO and IGT were significantly associated with incident diabetes in multivariate analysis (all HRs $>4, \mathrm{P}<0.001$ ); significant associations were also found for FPG and $2 \mathrm{~h}-\mathrm{PCPG}$ as continuous variables (all HRs for 1-SD increase $>2$, all $\mathrm{P}<0.001$ ).

Conclusions: Among subjects with stable CVD, both FPG and 2h-PCPG as continuous variables was associated with higher risk of recurrent CVD. However, only IFG-ADA was independent predictor of hard CVD events. Also, newly diagnosed diabetes, using FPG criteria, was associated with a significant risk of CVD. IFG-ADA, IFG-WHO and IGT were all significant predictors of incident diabetes.

\section{Background}

Cardiovascular disease (CVD) is one of the high-burden diseases among Middle East and North Africa (MENA) region and specially among Iranian population[1]. Individuals with a history of CVD are at high risk of recurrent CVD events and traditional CVD risk factors, the number of stenotic coronaries, the presence of heart failure, atrial fibrillation, cardiovascular treatment and geographic region were reported as main determinants in international models for predicting recurrent CVD [2,3]. Our previous study among patients with established CVD [4] showed that type 2 diabetes is associated with $>2$ folds higher risk of recurrent CVD events.

Impaired fasting glucose (IFG), impaired glucose tolerance (IGT) and newly diagnosed diabetes with a high incidence rate among Iranian population [5, 6] are common disorders among patients with CVD [7]. The association between prediabetes and newly diagnosed diabetes with recurrent CVD has been assessed in some short- and long- term hospital-based studies with inconsistent findings [8-11]. These studies were performed among patients with history of myocardial infarction ( $\mathrm{MI})$, coronary artery bypass graft (CABG), percutaneous coronary intervention (PCI) or history of acute coronary syndrome. According to these studies, an editorial by Riden et al [12] strongly recommend using oral glucose tolerance test (OGTT) for all patients with coronary artery disease (CAD) without known dysglycemia to improve the prediction of recurrent events. However, recently the investigators of ARTEMIS study [8], examined the prognostic significance of prediabetes among CAD patients in the stable phase of CAD. Findings showed that the presence of prediabetes, regardless of its definition, was not associated with higher incidence of major adverse cardiovascular events (MACE). To best of our knowledge, information on this controversial issue was poorly addressed in population-based studies, especially in regions with high burden of CVD.

In the current study, among Iranian subjects with stable CAD, we aimed to examine the association between FPG and 2 h-PCPG, whether as continues or categorical variables, with subsequent CVD/CHD and the related hard outcomes. Moreover, we examined these associations for incident type 2 diabetes in the oldest population-based cohort of MENA called the Tehran Lipid and Glucose Study (TLGS).

\section{Methods}

\section{Study population}

The present study was conducted within the framework of the TLGS, an ongoing large prospective community-based study of a representative urban sample of Tehran population with the aim of determining the prevalence and incidence of non-communicable disease and related risk factors.

Briefly, during first (1999-2002) and second phase (2002-2005), a total of 15,005 and 3551 people aged $\geq 3$ years, respectively, were enrolled and were followed at approximately 3 year intervals. Details of study design, sampling frame and rationale have been explained previously[13].

In the present study, among the 7116 participants aged $\geq 30$ years, 547 participants with prevalent CVD were included [361 from baseline (1999-2002) and 186 from second visit (2002-2005)]. After excluding those with known diabetes (i.e. those who were taking glucose-lowering medication at baseline visit, $\mathrm{n}=$ $117)$, missing data on covariates $(n=78)$ and those without any follow up after the baseline recruitment $(n=17), 335$ participants remained in our final study population and were followed until March 2016 (overall response rate 335/430 $\approx 78 \%$ ).

In the same data set, when considering incident diabetes as outcome, we further excluded 43 participants with newly diagnosed diabetes as well as 22 individuals with no follow-up information on diabetes, leaving us with data of 270 participants for analysis.

Page $2 / 10$ 


\section{Clinical And Laboratory Measurements}

Demographic information, medical history, smoking habits and history of CVD were obtained from participants during interviews, using a pretested questionnaire at baseline and each follow-up. Details of anthropometric measurements including weight, height and waist circumferences (WC) have been described elsewhere [13]. Body mass index (BMI) was calculated as weight in kilograms divided by square of height ( $\mathrm{m}^{2}$ ). Blood pressure was measured using a standardized mercury sphygmomanometer (calibrated by the Iranian Institute of Standards and Industrial Researches), twice on the right arm in a seated position after at least 15-minute rest and the mean of these two measurements, was considered as the participant's blood pressure.

Blood samples were taken between 7:00 and 9:00 AM after 12-14 h overnight fasting, and a standard oral glucose tolerance test (using 75 g glucose, for those without history of taking glucose-lowering medications) was performed. Details about measurements of serum glucose, total cholesterol (TC), triglycerides (TG), and high-density lipoprotein cholesterol (HDL-C) have been previously reported[13].

\section{Definition Of Terms}

For categorization of our study, we used both the American Diabetes Association (ADA) criteria [14] and World Health Organization (WHO) [15] criteria as follows: normal fasting glucose (NFG)-5.6: FPG < 5.6, NFG-6.1: FPG <6.1, normal glucose tolerance (NGT): 2 h-PCPG < 7.8, IFG-ADA: 5.6 $\leq$ FPG < 7 mmol/L, IFG-WHO: $6.1 \leq \mathrm{FPG}<7 \mathrm{mmol} / \mathrm{L}$ and, IGT: $7.8 \leq 2 \mathrm{~h}-\mathrm{PCPG}<11 \mathrm{mmol} / \mathrm{L}$. Newly diagnosed diabetes was defined by FPG criteria as FPG $\geq 7.0 \mathrm{mmol} / \mathrm{L}$ or by 2 -h $\mathrm{PCPG}$ criteria as $2 \mathrm{~h}-\mathrm{PCPG} \geq 11.0 \mathrm{mmol} / \mathrm{L}$ at first visit among those without history of taking glucose-lowering medication.

History of CVD included a history of acute coronary syndrome (ACS), definite coronary artery disease according to angiography results (> 50\% stenosis in at least one major coronary vessel), non-fatal $\mathrm{MI}, \mathrm{CABG}, \mathrm{PCl}$ and non-fatal stroke.

Positive family history of premature CVD was defined as history of CHD or stroke in a male first-degree relative aged < 55-year-old or female first-degree relative aged $<65$ years old. Positive family history of diabetes was determined as having a diabetic first- degree relative. Smoking status was described as current smoker versus non-smoker (reference group). Hypertension was defined as systolic blood pressure $\geq 140 \mathrm{~mm}-\mathrm{Hg}$ and/or diastolic blood pressure $\geq$ $90 \mathrm{~mm}-\mathrm{Hg}$ or using anti-hypertensive drugs. Hypercholesterolemia was described as total cholesterol (TC) levels $\geq 5.1 \mathrm{mmol} / \mathrm{L}$ and/or using lipid lowering medications. Hypertriglyceridemia was defined as TG $\geq 1.69 \mathrm{mmol} / \mathrm{L}$ and low $\mathrm{HDL}-\mathrm{C}$ as HDL-C $<1.06 \mathrm{mmol} / \mathrm{L}$ among men and $<1.29 \mathrm{mmol} / \mathrm{L}$ among women. [16]

\section{Outcomes}

Detailed definition of outcome data collection has been published previously.[17] Each participant in the TLGS is followed-up by telephone call from a trained nurse for any medical event leading to hospitalization during the past year and then a trained physician collects complementary data regarding that event during a home or hospital visit. In the case of mortality, data are collected from the hospital or death certificate by an authenticated local physician.

Collected data is then evaluated by an outcome committee (who were blinded to the status of baseline risk factors) including a principal investigator, an internist, an endocrinologist, a cardiologist, an epidemiologist, and other experts, when needed, to assign a specific outcome for every event. In the current study, CHD events included cases of 1)definite MI (positive electrocardiogram (ECG) and biomarkers), 2) probable MI (positive ECG findings plus cardiac symptoms or signs and normal or equivocal biomarkers), 3) unstable angina pectoris (new cardiac symptoms or changing symptom patterns and positive ECG findings with normal biomarkers) 4) angiography proven CHD, and 5) CHD death (any death in hospital due to CHD or sudden cardiac death caused by cardiac disease occurring $\leq 1$ hour after beginning of symptoms).[18] Furthermore, CVD was clarified as a composite of CHD events, and cerebrovascular events (transient ischemic attack (TIA), ischemic or hemorrhagic stroke and cerebrovascular death). Hard CHD events were defined as the occurrence of nonfatal MI and CHD death and hard CVD event considered as nonfatal MI, nonfatal stroke and CVD death.[19]

\section{Statistical analysis}

Baseline characteristics are expressed as mean (SD) and median (interquartile range) for continuous variables with and without normal distribution, respectively and number (\%) for categorical ones across the NFG, IFG and newly diagnosed diabetes. To compare the baseline characteristics across all number of live births, ANOVA (or Kruskal-Wallis for the variable with non-normal distribution) and chi-square tests were employed for continuous and categorical variables, respectively.

Potential risk factors were identified based on clinical importance, review of literature [20] and statistical significance in univariate analysis and were included in the multivariate Cox proportional hazard models to evaluate associations of the different glucose intolerance categories with incident CVD, hard CVD, CHD, hard CHD and diabetes separately, using NFG-5.6 or NFG-6.1 or $2 \mathrm{~h}-\mathrm{PCPG}<7.8 \mathrm{mmol} / \mathrm{L}$ as reference.

Time to event was defined as time of censoring or date of the incidence of CVD/CHD and related hard outcomes, whichever occurred first. We censored subjects at the time of other causes of non- CVD death, leaving the district or being in the study until 20 March 2016, without any event. The event date for individuals with diabetes was defined as the middle-time between the first and the final follow-up visit. The follow-up time was the difference between the calculated mid-time date and the enter date. For the censored and lost to follow-up individuals the survival time was calculated as the interval between the first and final follow-up visit. 
In the multivariate analysis, two models were designed: model 1 included sex and baseline measurements of age. When considering incident CVD, hard CVD, CHD and hard CHD as outcomes, model 2 included further adjustment for BMI, current smoking, family history of premature CVD, hypertension,

hypercholesterolemia, heart rate and use of aspirin. Moreover, for those with incident diabetes as outcome, model 2 included adjustment for age, sex, BMI, WC, family history of diabetes, hypertriglyceridemia and low HDL-C level.

The proportionality in the Cox model was evaluated with the Schoenfild residual test and generally, all proportionality assumptions were appropriate. Statistical analysis was performed using STATA version 14 (Stata Corp LP, College Station, Texas), statistical software. P- values $<0.05$ were considered statistically significant.

\section{Results}

Of 335 subjects with previous CVD, 87 subjects had acute coronary syndrome, 128 had definite coronary artery disease, 63 had non-fatal MI, 9 had CABG, 5 had history of $\mathrm{PCl}$ and 43 had non-fatal stroke (Fig. 1). Baseline characteristics of subjects by glucose tolerance category according to ADA criteria are shown in Table 1. The mean (SD) age of total population was 60.5(10.15) years and 61.5\% were men. Generally, there was a significant increasing trend regarding BMI, FPG and 2 h-PCPG from subjects with NFG to those with IFG and newly diagnosed diabetes; this trend was marginally significant for triglycerides.

Table 1

Baseline characteristics of the study population

\begin{tabular}{|c|c|c|c|c|c|}
\hline & $\begin{array}{l}\text { NFG } \\
(n=220)\end{array}$ & $\begin{array}{l}\text { IFG-ADA } \\
(n=95)\end{array}$ & Newly diagnosed diabetes $(n=20)$ & P-Value & $\begin{array}{l}\text { Total population } \\
(n=335)\end{array}$ \\
\hline \multicolumn{6}{|l|}{ Continuous variables, mean(SD) } \\
\hline Age(years) & $60.07(10.44)$ & 61.36(9.83) & $61.27(8.45)$ & 0.5 & $60.5(10.15)$ \\
\hline $\mathrm{BMI}\left(\mathrm{kg} / \mathrm{m}^{2}\right)$ & $27.45(4.37)$ & $28.99(4.78)$ & $30.46(5.46)$ & 0.001 & $28.07(4.63)$ \\
\hline $\mathrm{WC}(\mathrm{cm})$ & 75.7(11.9) & 78.1(12.7) & $77.5(8.8)$ & 0.25 & 76.5(12.2) \\
\hline $\mathrm{SBP}(\mathrm{mm}-\mathrm{Hg})$ & 128.11(20.8) & 132.94(20.4) & $136.05(22.4)$ & 0.07 & 129.96(20.9) \\
\hline $\mathrm{DBP}(\mathrm{mm}-\mathrm{Hg})$ & $78.12(12.5)$ & 77.83(10.7) & $81.9(10.8)$ & 0.36 & 78.27(11.9) \\
\hline HR(beat/minute) & $95.3(10.2)$ & $98.8(9.4)$ & 102.8(10.3) & $<0.001$ & $96.7(10.2)$ \\
\hline $\mathrm{FPG}(\mathrm{mmol} / \mathrm{l})$ & $4.96(0.3)$ & $6.01(0.3)$ & $8.60(1.44)$ & $<0.001$ & $5.5(1.04)$ \\
\hline $2 \mathrm{~h}-\mathrm{PCPG}(\mathrm{mmol} / \mathrm{l})$ & $6.37(1.89)$ & $8.72(2.65)$ & $16.99(4.70)$ & $<0.001$ & 7.67(3.49) \\
\hline $\mathrm{TC}(\mathrm{mmol} / \mathrm{L})$ & $5.34(1.13)$ & $5.40(1.06)$ & $5.96(1.48)$ & 0.07 & $5.40(1.14)$ \\
\hline $\mathrm{HDL}-\mathrm{C}(\mathrm{mmol} / \mathrm{L})$ & $1.01(0.47)$ & $1.00(0.54)$ & $0.99(0.6)$ & 0.29 & $0.97(0.47)$ \\
\hline Triglycerides $(\mathrm{mmol} / \mathrm{L})^{a}$ & $1.75(0.54-7.14)$ & $1.83(0.62-11.67)$ & $2.56(0.62-10.85)$ & 0.06 & $1.77(1.24-2.55)$ \\
\hline \multicolumn{6}{|l|}{ Categorical variables, n (\%) } \\
\hline Gender (men) & $139(63.2)$ & $53(55.8)$ & 14(70.0) & 0.3 & $206(61.5)$ \\
\hline Family history of CVD & $36(16.4)$ & $15(15.8 \%)$ & $1(5.0 \%)$ & 0.4 & $52(15.5 \%)$ \\
\hline Current smoking & $37(16.8)$ & 15(15.8) & $4(20.0)$ & 0.8 & $56(16.7)$ \\
\hline Hypertension & $115(52.3)$ & $55(57.9)$ & $12(60.0)$ & 0.5 & 182(54.3) \\
\hline Hypercholesterolemia & $133(60.5)$ & $55(57.9)$ & $13(65.0)$ & 0.8 & $201(60.0)$ \\
\hline \multicolumn{6}{|l|}{ Medications } \\
\hline Anti-hypertensive medication & 73(33.2) & 32(33.7) & $7(35.0)$ & 0.98 & 112(33.4) \\
\hline Lipid-lowering medication & $24(10.9)$ & $10(10.5)$ & $3(15.0)$ & 0.84 & $37(11.0)$ \\
\hline Aspirin use & $109(49.5)$ & $43(45.3)$ & $12(60.0)$ & 0.46 & $164(49.0)$ \\
\hline
\end{tabular}

During the median follow-up of 15.8 (IQR, 10.7-16.5) years, 178 CVD (hard event $=69)$ and 164 CHD (hard event $=45$ ) events occurred. Risks of adverse cardiovascular outcomes based on different glucose intolerance categories are illustrated in Table 2 for age and sex adjusted model and Fig. 2 for multivariate model. Subjects with IFG using both WHO and ADA definitions were at no statistically significant higher risk of CVD/CHD even in age and sex adjusted model. Regarding hard outcomes, only IFG-ADA was associated with significant higher risk of hard CVD in the fully adjusted model; HR, 1.73 [95\% Cl: $1.04-2.89, P=0.03]$. 
Table 2

Age and sex adjusted risks of adverse cardiovascular outcomes based on different glucose intolerance categories. $(n=335)$

\begin{tabular}{|c|c|c|c|c|c|c|c|c|c|c|c|c|}
\hline & & $\begin{array}{l}\text { CVD } \\
\text { HR } \\
(95 \% \mathrm{Cl})\end{array}$ & & & $\begin{array}{l}\text { Hard CVD } \\
\text { HR } \\
(95 \% \mathrm{Cl})\end{array}$ & & & $\begin{array}{l}\text { CHD } \\
\text { HR } \\
(95 \% \mathrm{Cl})\end{array}$ & & & $\begin{array}{l}\text { Hard CHD } \\
\text { HR } \\
(95 \% \mathrm{Cl})\end{array}$ & \\
\hline $\mathrm{E} / \mathrm{N}$ & & Model 1 & $\begin{array}{l}P \text { - } \\
\text { value }\end{array}$ & $\mathrm{E} / \mathrm{N}$ & Model 1 & $\begin{array}{l}\mathrm{P} \text { - } \\
\text { value }\end{array}$ & $\mathrm{E} / \mathrm{N}$ & Model 1 & $\begin{array}{l}\mathrm{P}- \\
\text { value }\end{array}$ & $\mathrm{E} / \mathrm{N}$ & Model 1 & $\begin{array}{l}P \text { - } \\
\text { value }\end{array}$ \\
\hline \multicolumn{13}{|c|}{ FPG-WHO (mmol/L) } \\
\hline $\begin{array}{l}< \\
6.1 \mathrm{mmol} / \mathrm{L}\end{array}$ & $144 / 279$ & 1.00 & & $55 / 279$ & 1.00 & & $132 / 297$ & 1.00 & & $34 / 279$ & 1.00 & \\
\hline $6.1-6.9$ & $18 / 36$ & $\begin{array}{l}1.03(0.63- \\
1.69)\end{array}$ & 0.90 & $9 / 36$ & $\begin{array}{l}1.45(0.72- \\
2.94)\end{array}$ & 0.30 & $16 / 36$ & $\begin{array}{l}0.96(0.57- \\
1.61)\end{array}$ & 0.87 & $6 / 36$ & $\begin{array}{l}1.51(0.63- \\
3.60)\end{array}$ & 0.35 \\
\hline$\geq 7$ & $16 / 20$ & $\begin{array}{l}2.18(1.29- \\
3.67)\end{array}$ & 0.004 & $5 / 20$ & $\begin{array}{l}1.42(0.56- \\
3.53)\end{array}$ & 0.46 & $16 / 20$ & $\begin{array}{l}2.37(1.40- \\
4.01)\end{array}$ & 0.001 & $5 / 20$ & $\begin{array}{l}2.19(0.85- \\
5.61)\end{array}$ & 0.10 \\
\hline \multicolumn{13}{|c|}{ FPG-ADA(mmol/L) } \\
\hline$<5.6$ & $112 / 220$ & 1.00 & & $38 / 220$ & 1.00 & & $104 / 220$ & 1.00 & & $26 / 220$ & 1.00 & \\
\hline $5.6-6.9$ & $50 / 95$ & $\begin{array}{l}1.13(0.81- \\
1.59)\end{array}$ & 0.45 & $26 / 95$ & $\begin{array}{l}1.84(1.11- \\
3.04)\end{array}$ & 0.02 & $44 / 95$ & $\begin{array}{l}1.05(0.74- \\
1.50)\end{array}$ & 0.78 & $14 / 95$ & $\begin{array}{l}1.40(0.73- \\
2.70)\end{array}$ & 0.31 \\
\hline$\geq 7$ & $16 / 20$ & $\begin{array}{l}2.25(1.32- \\
3.82)\end{array}$ & 0.003 & $5 / 20$ & $\begin{array}{l}1.65(0.65- \\
4.22)\end{array}$ & 0.29 & $16 / 20$ & $\begin{array}{l}2.42(1.42- \\
4.12)\end{array}$ & 0.001 & $5 / 20$ & $\begin{array}{l}2.31(0.88- \\
6.04)\end{array}$ & 0.09 \\
\hline \multicolumn{13}{|c|}{$2 \mathrm{~h}-\mathrm{PCPG}(\mathrm{mmol} / \mathrm{L})$} \\
\hline$<7.8$ & $107 / 212$ & 1.00 & & $44 / 212$ & 1.00 & & $97 / 212$ & 1.00 & & $27 / 212$ & 1.00 & \\
\hline $7.8-11.0$ & $45 / 82$ & $\begin{array}{l}1.12(0.79- \\
1.59)\end{array}$ & 0.51 & $15 / 82$ & $\begin{array}{l}0.88(0.49- \\
1.58)\end{array}$ & 0.67 & $42 / 82$ & $\begin{array}{l}1.13(0.78- \\
1.62)\end{array}$ & 0.51 & $9 / 82$ & $\begin{array}{l}0.87(0.41- \\
1.85)\end{array}$ & 0.72 \\
\hline$\geq 11$ & $26 / 41$ & $\begin{array}{l}1.40(0.91- \\
2.16)\end{array}$ & 0.12 & $10 / 41$ & $\begin{array}{l}1.38(0.69- \\
2.76)\end{array}$ & 0.35 & $25 / 41$ & $\begin{array}{l}1.50(0.96- \\
2.34)\end{array}$ & 0.07 & $9 / 41$ & $\begin{array}{l}2.07(0.97- \\
4.42)\end{array}$ & 0.06 \\
\hline \multicolumn{13}{|c|}{$\begin{array}{l}\text { E, event in the target group; } \mathrm{N} \text {, total sample size in the target group; } \mathrm{CVD} \text {, cardiovascular disease; } \mathrm{CHD} \text {, coronary heart disease; HR, hazard ratios; } \mathrm{Cl} \text {, } \\
\text { confidence interval; FPG, fasting plasma glucose; } 2 \text { h-PCPG, 2-h post challenge plasma glucose; WHO, World Health Organization; } \mathrm{ADA} \text {, American Diabetes } \\
\text { Association. } \\
\text { Model 1: age and sex }\end{array}$} \\
\hline
\end{tabular}

Subjects with newly diagnosed type 2 diabetes using FPG definition, in both IFG-WHO and IFG- ADA datasets, were at a significant > 2-fold higher risk of CVD 2.05[(1.19-3.51), $P=0.009]$ and CHD 2.23[(1.29-3.85), $P=0.004]$ compared to subjects with NFG in the fully adjusted model. Regarding hard events, although the newly diagnosed diabetes was associated with HRs range between 1.46 [(0.56-3.79), $\mathrm{P}=0.44]$ for hard $\mathrm{CVD}$ to 2.45 [(0.88-6.82), $\mathrm{P}=0.09]$ for hard $\mathrm{CHD}$; these values did not reach to significant level after considering traditional risk factors, considering wide $\mathrm{Cl}$ due to limited number of events.

Focusing on $2 \mathrm{~h}-\mathrm{PCPG}$, subjects with IGT were at no significant higher risk of CVD/CHD and the related hard outcomes compared with those with $2 \mathrm{~h}-\mathrm{PCPG}<$ $7.8 \mathrm{mmol} / \mathrm{L}$. Regarding newly diagnosed type 2 diabetes $(2 \mathrm{~h}-\mathrm{PCPG} \geq 11.0 \mathrm{mmol} / \mathrm{L})$ in the fully adjusted model the HRs range from $1.36[(0.88-2.12), \mathrm{P}=$ 0.17 ] for CVD to 2.02 [(0.91-4.47), $P=0.08]$ for hard $C H D$; the values however, did not reach to the significant level.

As shown in Table 3, when FPG modeled as continuous variable, HRs (95\% Cl) associated with a 1 SD increase in FPG were 1.16 (1.01-1.33) for CVD and 1.17 (1.01-1.35) for CHD in the fully adjusted model; the corresponding values for $2 \mathrm{~h}$-PCPG were 1.19 (1.02-1.38) and 1.22 (1.04-1.42), respectively. Moreover, when both FPG and 2 h-PCPG were entered in the same model, risk of CVD/CHD was not significant for these variables. (data not shown) 
Table 3

Adjusted HR $(95 \% \mathrm{Cl})$ for adverse cardiovascular outcomes per 1-SD increase of FPG and $2 \mathrm{~h}-\mathrm{PCPG} .(\mathrm{n}=335)$

\begin{tabular}{|c|c|c|c|c|c|c|c|c|}
\hline & \multicolumn{2}{|l|}{ CVD } & \multicolumn{2}{|l|}{ Hard CVD } & \multicolumn{2}{|l|}{ CHD } & \multicolumn{2}{|l|}{ Hard CHD } \\
\hline & $\mathrm{HR}(95 \% \mathrm{Cl})$ & P-value & $\mathrm{HR}(95 \% \mathrm{Cl})$ & P-value & $\mathrm{HR}(95 \% \mathrm{Cl})$ & P-value & $\mathrm{HR}(95 \% \mathrm{Cl})$ & P-value \\
\hline \multicolumn{9}{|l|}{ FPG } \\
\hline Model 1 & $1.18(1.03-1.35)$ & 0.01 & $1.12(0.91-1.38)$ & 0.27 & $1.19(1.04-1.37)$ & 0.01 & $1.16(0.91-1.48)$ & 0.24 \\
\hline Model 2 & $1.16(1.01-1.33)$ & 0.03 & $1.13(0.91-1.40)$ & 0.27 & $1.17(1.01-1.35)$ & 0.03 & $1.16(0.90-1.51)$ & 0.25 \\
\hline \multicolumn{9}{|c|}{2 h-PCPG } \\
\hline Model 1 & $1.20(1.04-1.38)$ & 0.1 & $1.08(0.85-1.36)$ & 0.54 & $1.22(1.06-1.42)$ & 0.01 & $1.19(0.92-1.54)$ & 0.18 \\
\hline Model 2 & $1.19(1.02-1.38)$ & 0.02 & $1.08(0.85-1.38)$ & 0.50 & $1.22(1.04-1.42)$ & 0.01 & $1.21(0.92-1.59)$ & 0.17 \\
\hline
\end{tabular}

Among 270 subjects with prevalent CVD and free of diabetes at baseline, 64 incident diabetes occurred during follow up with incidence rate of 26.53(20.7633.89) per 1000 persons-years. As shown in Table 4, both IFG-WHO 4.47 [(2.36-8.47), P< 0.001 and IFG-ADA 4.14 [(2.47-6.93), P < 0.001] were associated with significant risk for developing incident diabetes in the fully adjusted model. Moreover, IGT was associated with over 6-fold higher risk in the fully adjusted model 6.10[(3.58-10.39), P<0.001]. Also, HRs $(95 \% \mathrm{Cl})$, per each 1-SD increase in FPG and $2 \mathrm{~h}-\mathrm{PCPG}$ for incident diabetes in the fully adjusted model were $2.36[(1.81-3.09), P<0.001]$ and $3.23[(2.39-4.36), P<0.001]$, respectively.

In the sensitivity analysis, we repeated our analysis after excluding those with stroke at baseline $(n=43)$; results were generally in line with those of the main findings. (Supplementary tables 1 and 2). To compare our findings with those of other studies we defined abnormal glucose tolerance (AGT) as 2-hPCPG $\geq$ $7.8 \mathrm{mmol} / \mathrm{L}$ versus $2-\mathrm{hPCPG}<7.8 \mathrm{mmol} / \mathrm{L}$ (reference group). Accordingly, AGT similar to IGT was not associated with any cardiovascular outcome. (data not shown)

\section{Discussion}

This population-based cohort study was conducted among subjects with stable CVD without known diabetes with over a decade follow-up. We examined the associations between FPG and 2 h-PCPG, whether as continuous or categorical variables, and recurrent CVD/CHD and related hard outcomes. Firstly, we found out that as for FPG level, IFG-ADA was associated with $73 \%$ higher risk of hard CVD events and newly diagnosed diabetes was associated with 2-fold higher risk of recurrent CVD/CHD events, independent of traditional risk factors. Secondly, every $1.04 \mathrm{mmol} / \mathrm{L}$ increase in FPG was associated with $16 \%$ higher risk of CVD. Thirdly, as for $2 \mathrm{~h}-\mathrm{PCPG}$, subjects with newly diagnosed diabetes ( $2 \mathrm{~h}-\mathrm{PCPG} \geq 11.1 \mathrm{mmol} / \mathrm{L}$ ) had moderately increased risk of hard coronary heart disease, moreover, every $3.49 \mathrm{mmol} / \mathrm{L}$ higher levels of $2 \mathrm{~h}-\mathrm{PCPG}$ was associated with $19 \%$ risk of CVD. Fourthly, FPG and 2 h-PCPG, whether as continues or categorical variables were significant predictors of incident diabetes.

Impact of IFG, IGT and newly diagnosed diabetes on recurrent cardiovascular outcomes has been addressed in previous studies; however, there were significant differences between them as follows: Firstly, most of them were performed among admitted patients with high baseline risk for recurrent event i.e., those with MI [10,11, 21-25] who had data on OGTT before discharging from hospital or those with history of PCI/CABG[9]. Secondly, there was a great difference between studies in terms of sample size, follow-up duration, approaching FPG and $2 \mathrm{~h}-\mathrm{PCPG}$ as a continuous or categorical variable and heterogeneity in outcome definitions (CVD, MACE, all-cause or cardiovascular mortality). To our knowledge, this is the first population-based study with a longterm follow-up to asses this association in a heterogenic and relatively low risk population with stable CVD.

Findings of previous studies regarding the association between FPG (whether as continuous or categorical variable) with recurrent CVD were heterogenic. Accordingly, FPG as a continuous variable was not associated $[8,9,26]$ or had lower risk $0.85[0.71-1.01), P=0.06]$ of recurrent $C V D[22,27]$; whereas each $1 \mathrm{mmol} / \mathrm{L}$ increase in FPG was associated with higher risk of MACE (28\%) and cardiovascular mortality (51\%) among post MI patients in UK; the risks however, were not significant in the models including both FPG and $2 \mathrm{~h}-\mathrm{PCPG}$ [28]. The finding of the current study showed that each $1.04 \mathrm{mmol} / \mathrm{L}$ increase in FPG was associated with $16 \%$ and $17 \%$ higher risk of CVD and CHD, respectively. When including both FPG and 2 h-PCPG in the same model, no association was found between glucose variables and different cardiovascular events.

Moreover, when using standard cut-offs among patients with prevalent CAD, IFG-WHO was not associated with MACE in the study of Tamita [1.86(0.86-3.87)] [11], any cardiac outcomes in the study by Kiviniemi et al [8] and composite endpoints (including cardiovascular mortality, non-fatal Ml, stroke, or hospitalization for heart failure) in the study by Shahim et al.[9]. Furthermore, in a population-based study among men in Japan, borderline hyperglycemia (FPG = 5.6-6.9 mmol/L) among those with prior CAD was not associated with recurrent CVD outcomes.[29] Similarly, prediabetes (FPG of 5.6-6.9 mmol/L, and $\mathrm{HbA1c}<39 \mathrm{mmol} / \mathrm{L}$ ) was not associated with 2-year MACE and hard cardiovascular outcomes in Chinese patients after PCl.[30] Besides, Lenzen et al [31] revealed that impaired glucose regulation (those with IFG and IGT) was not an independent predictor for hard CVD outcomes in the multicenter hospital-based setting. The findings of the current study, however, showed that among stable outpatient CAD patients, IFG-ADA was associated with $73 \%$ risk for hard CVD (including definite MI or stroke and CVD mortality) and was in line with the study conducted by Otten et al [32] that showed IFG-ADA was associated with a hazard of 1.66 [(1.05-2.61)] for MACE. Importantly, among general population, we have recently shown that the significant risk of IFG for CVD events was 
attributable to those population who converted from IFG state to diabetes.[33] Unfortunately, in the current study, we did not have adequate power to check this possibility in a cohort of subjects with history of previous CVD.

Focusing on 2 h-PCPG, some studies suggest that $2 \mathrm{~h}-\mathrm{PCPG}$ is a better determinant for assessing the prognosis of post ACS patients than FPG. Notably, some authors suggest that adding 2 h-PCPG (but not FPG) to the Global Registry of Acute Coronary Events (GRACE) score (an established risk model for recurrent cardiac events), can improve the prediction power of the model in post MI patients without known diabetes[22, 27]. Furthermore, the finding of the study by Chattopadhyay showed that $2 \mathrm{~h}-\mathrm{PCPG}$ as a continues variable is a better predictor of adverse post Ml outcomes compared to FPG [28]. In this regard, our study showed a positive association between $2 \mathrm{~h}-\mathrm{PCPG}$ as a continuous variable and recurrent CVD/CHD outcomes as each $3.49 \mathrm{mmol} / \mathrm{L}$ increase in $2 \mathrm{~h}-$ PCPG was associated with $19 \%$ and $22 \%$ higher risk of CVD and CHD, respectively. Moreover, finding of some studies showed that IGT was associated with worse post MI prognosis [9, 22] while some showed no significant risk [26] and study by George et al [23] revealed that IGT is associated with higher risk of MACE but not hard CVD outcomes. The findings of our study however, showed that the risk of CVD/CHD and the related hard outcomes does not increase among those with IGT; in line with other studies conducted among low risk population with prevalent CAD [8, 34].

Focusing on newly diagnosed diabetes, we found that newly diagnosed diabetes using FPG criteria was associated with CVD/CHD but not hard cardiovascular outcomes. In line with our study, the findings of a cohort study on Chinese patients who underwent PCI [30] showed that newly diagnosed diabetes (FPG $\geq 7.0 \mathrm{mmol} / \mathrm{L}$ or $\mathrm{HbA} 1 \mathrm{c} \geq 48 \mathrm{mmol} / \mathrm{L}$ ) was an independent risk factor for MACE but not hard outcomes. Moreover, study conducted by George et al, [23] showed that newly diagnosed diabetes (FPG $\geq 7.0$ and/or $2 \mathrm{~h}-\mathrm{PCPG} \geq 11.1 \mathrm{mmom} / \mathrm{L}$ ) was associated with CVD and related hard outcomes. However, in the EUROASPIRE IV study [9] newly diagnosed diabetes (FPG $\geq 7$ ) was not associated with composite cardiovascular outcomes. Similarly, newly diagnosed diabetes was not associated with MI, stroke and hard CVD outcomes in the study among European population [31]. Regarding the newly diagnosed diabetes using 2 h-PCPG criteria, most studies showed that newly diagnosed diabetes [21, 26] or AGT (newly diagnosed diabetes using $2 \mathrm{~h}-\mathrm{PCPG}$ definition plus IGT) are independently associated with higher risk of different cardiovascular outcomes [9-11, 24-26]. In the current study however, when using $2 \mathrm{~h}$ PCPG criteria, a moderate higher risk of hard CHD 2.02 [(0.91-4.47), P = 0.08] was seen among those with newly diagnosed diabetes. However, AGT was not associated with different cardiovascular outcomes.

Our findings showed that both FPG and 2 h-PCPG, whether as continuous or categorical are strong predictors of incident diabetes. This is while 2 h-PCPG but not FPG was a significant predictor in the EUROASPIRE IV study[9]. However, as we have shown in our previous study[20] history of CVD per se is not an independent risk factor for incident diabetes.

Strengths of the current study are its prospective, longitudinal design with a long-term follow-up, reliable measurements of different covariates and careful adjustment for potential confounders. Moreover, our study included a heterogenic group of subjects with history of CAD in the stable phase of the disease and evaluated a wide range of outcomes including hard CVD/CHD events. This study also had some limitation: Firstly, we did not have data to calculate GRACE score including the ejection fraction of subjects, however, the available variables of this score system such as heart rate, were included in the multivariate model. Secondly, we did not have data of HbA1c levels which may cause misclassification and underestimation of the risk associated with prediabetes. Finally, this study was conducted on an Iranian population and the findings cannot be extrapolated to other ethnicities.

\section{Conclusion}

The present study, showed that except for the significant association between IFG-ADA and hard CVD events none of other different prediabetes phenotypes i.e., IFG-WHO and IGT were associated with cardiovascular and related hard outcomes. Moreover, only those with newly diagnosed diabetes using FPG definition but not $2 \mathrm{~h}$-PCPG definition were at higher risk of CVD/CHD. Furthermore, each $1.04 \mathrm{mmol} / \mathrm{L}$ increase in FPG and $3.49 \mathrm{mmol} / \mathrm{L}$ higher levels of $2 \mathrm{~h}$ PCPG were associated with significant risk of recurrent CVD/CHD. Finally, FPG and $2 \mathrm{~h}-\mathrm{PCPG}$, as either continues or categorical variables were significant predictors of incident diabetes. These findings show that among a cohort of Iranian subjects with stable CVD, newly diagnosed diabetes and IFG-ADA were associated with higher risk of recurrent CVD events. These findings could be employed to design prevention strategies for reducing the risk of CVD/CHD events.

\section{Abbreviations}

cardiovascular disease (CVD), coronary heart disease (CHD), normal fasting glucose (NFG), normal glucose tolerance (NGT), impaired fasting glucose (IFG), impaired glucose tolerance (IGT), hazard ratio (HR), confidence interval (CI), standard deviation (SD) Middle East and North Africa (MENA), Tehran Lipid and Glucose Study (TLGS), fasting plasma glucose (FPG), 2-h post challenge plasma glucose (2 h-PCPG), body mass index (BMI), waist circumference (WC), systolic blood pressure (SBP) and diastolic blood pressure (DBP), total cholesterol (TC), High density lipoprotein-cholesterol (HDL-C), electrocardiogram (ECG), American Diabetes Association (ADA), World Health Organization (WHO), myocardial infarction (MI).

\section{Declarations}

Ethics approval and consent to participate: All participants gave written informed consents according to the Helsinki Declaration guideline and the study was approved by local ethics committee (medical ethics committee of the Research Institute for Endocrine Sciences)

Consent for publication: All authors have declared their consent for this publication.

Availability of data and materials: All data and materials are available upon request.

Competing interest: None declared. 
Funding: This research did not receive any specific grant from funding agencies in the public, commercial, or not-for-profit sectors.

Author contributions: FH, MK, and FA conceived and planned the study. SA conducted the analyses. MK, SMGH, and FH developed the first draft of the manuscript. All authors contributed to the writing of the paper, and have read and approved the final manuscript.

Acknowledgements: We would also like to express our appreciation to the research team members and to TLGS participants for their enthusiastic support. The authors wish to acknowledge Dr. Fatemeh Moosaie for critical editing of English grammar and syntax of the manuscript.

\section{References}

1. Khalili D, Sheikholeslami FH, Bakhtiyari M, Azizi F, Momenan AA, Hadaegh F. The incidence of coronary heart disease and the population attributable fraction of its risk factors in Tehran: a 10-year population-based cohort study. PloS one. 2014;9(8):e105804.

2. Wilson PW, D'Agostino Sr R, Bhatt DL, Eagle K, Pencina MJ, Smith SC, Alberts MJ, Dallongeville J, Goto S, Hirsch AT. An international model to predict recurrent cardiovascular disease. Am J Med. 2012;125(7):695-703. e691.

3. Barbero U, D'Ascenzo F, Nijhoff F, Moretti C, Biondi-Zoccai G, Mennuni M, Capodanno D, Lococo M, Lipinski MJ, Gaita F: Assessing risk in patients with stable coronary disease: when should we intensify care and follow-up? Results from a meta-analysis of observational studies of the COURAGE and FAME era. Scientifica 2016, 2016.

4. Taravatmanesh S, Khalili D, Khodakarim S, Asgari S, Hadaegh F, Azizi F, Sabour S. Determining the Factors Associated with Cardiovascular Disease Recurrence: Tehran Lipid and Glucose Study. The Journal of Tehran University Heart Center. 2017;12(3):107.

5. Hadaegh F, Derakhshan A, Zafari N, Khalili D, Mirbolouk M, Saadat N, Azizi F. Pre-diabetes tsunami: incidence rates and risk factors of pre-diabetes and its different phenotypes over 9 years of follow-up. Diabet Med. 2017;34(1):69-78.

6. Eslami A, Mozaffary A, Derakhshan A, Azizi F, Khalili D, Hadaegh F. Sex-specific incidence rates and risk factors of premature cardiovascular disease. A Iong term follow up of the Tehran Lipid and Glucose Study. Int J Cardiol. 2017;227:826-32.

7. Bartnik M, Malmberg K, Hamsten A, Efendic S, Norhammar A, Silveira A, Tenerz Å, Öhrvik J, Rydén L. Abnormal glucose tolerance-a common risk factor in patients with acute myocardial infarction in comparison with population-based controls. Journal of internal medicine. 2004;256(4):288-97.

8. Kiviniemi AM, Lepojärvi ES, Tulppo MP, Piira O-P, Kenttä TV, Perkiömäki JS, Ukkola OH, Myerburg RJ, Junttila MJ, Huikuri HV. Prediabetes and Risk for Cardiac Death Among Patients With Coronary Artery Disease: The ARTEMIS Study. Diabetes Care. 2019;42(7):1319-25.

9. Shahim B, De Bacquer D, De Backer G, Gyberg V, Kotseva K, Mellbin L, Schnell O, Tuomilehto J, Wood D, Rydén L. The prognostic value of fasting plasma glucose, two-hour postload glucose, and HbA1c in patients with coronary artery disease: a report from EUROASPIRE IV: a survey from the European Society of Cardiology. Diabetes Care. 2017;40(9):1233-40.

10. Tamita K, Katayama M, Takagi T, Akasaka T, Yamamuro A, Kaji S, Morioka S, Kihara Y. Impact of newly diagnosed abnormal glucose tolerance on longterm prognosis in patients with acute myocardial infarction. Circ J. 2007;71(6):834-41.

11. Tamita K, Katayama M, Takagi T, Yamamuro A, Kaji S, Yoshikawa J, Furukawa Y. Newly diagnosed glucose intolerance and prognosis after acute myocardial infarction: comparison of post-challenge versus fasting glucose concentrations. Heart. 2012;98(11):848-54.

12. Rydén L, Shahim B, Standl E. On the prognostic value of post-load glucose in patients with coronary artery disease. European heart journal 2018.

13. Azizi F, Ghanbarian A, Momenan AA, Hadaegh F, Mirmiran P, Hedayati M, Mehrabi Y, Zahedi-AsI S. Prevention of non-communicable disease in a population in nutrition transition: Tehran Lipid and Glucose Study phase II. Trials. 2009;10(1):5.

14. Association AD. Standards of Medical Care in Diabetes-2020 abridged for primary care providers. Clinical Diabetes. 2020;38(1):10-38.

15. Organization WH: Use of glycated haemoglobin (HbA1c) in diagnosis of diabetes mellitus: abbreviated report of a WHO consultation. In.: World Health Organization; 2011.

16. Sardarinia M, Akbarpour S, Lotfaliany M, Bagherzadeh-Khiabani F, Bozorgmanesh M, Sheikholeslami F, Azizi F, Hadaegh F. Risk factors for incidence of cardiovascular diseases and all-cause mortality in a middle eastern population over a decade follow-up: Tehran lipid and glucose study. PloS one 2016, 11(12).

17. Hadaegh F, Harati H, Ghanbarian A, Azizi F. Association of total cholesterol versus other serum lipid parameters with the short-term prediction of cardiovascular outcomes: Tehran Lipid and Glucose Study. European Journal of Cardiovascular Prevention Rehabilitation. 2006;13(4):571-7.

18. Luepker RV, Apple FS, Christenson RH, Crow RS, Fortmann SP, Goff D, Goldberg RJ, Hand MM, Jaffe AS, Julian DG: Case definitions for acute coronary heart disease in epidemiology and clinical research studies: a statement from the AHA Council on Epidemiology and Prevention; AHA Statistics Committee; World Heart Federation Council on Epidemiology and Prevention; the European Society of Cardiology Working Group on Epidemiology and Prevention; Centers for Disease Control and Prevention; and the National Heart, Lung, and Blood Institute. Circulation 2003, 108(20):2543-2549.

19. Lehmann N, Erbel R, Mahabadi AA, Rauwolf M, Möhlenkamp S, Moebus S, Kälsch H, Budde T, Schmermund A, Stang A. Value of progression of coronary artery calcification for risk prediction of coronary and cardiovascular events: result of the HNR Study (Heinz Nixdorf Recall). Circulation. 2018;137(7):665-79.

20. Derakhshan A, Sardarinia M, Khalili D, Momenan AA, Azizi F, Hadaegh F. Sex specific incidence rates of type 2 diabetes and its risk factors over 9 years of follow-up: Tehran Lipid and Glucose Study. PloS one 2014, 9(7).

21. Kitada S, Otsuka Y, Kokubu N, Kasahara Y, Kataoka Y, Noguchi T, Goto Y, Kimura G, Nonogi H. Post-load hyperglycemia as an important predictor of longterm adverse cardiac events after acute myocardial infarction: a scientific study. Cardiovascular diabetology. 2010;9(1):75. 
22. Chattopadhyay S, George A, John J, Sathyapalan T. Pre-diabetes mellitus newly diagnosed after myocardial infarction adversely affects prognosis in patients without known diabetes. Diabetes Vascular Disease Research. 2019;16(6):489-97.

23. George A, Bhatia RT, Buchanan GL, Whiteside A, Moisey RS, Beer SF, Chattopadhyay S, Sathyapalan T, John J. Impaired glucose tolerance or newly diagnosed diabetes mellitus diagnosed during admission adversely affects prognosis after myocardial infarction: an observational study. PLOS One 2015, 10(11).

24. Ritsinger V, Tanoglidi E, Malmberg K, Näsman P, Rydén L, Tenerz Å, Norhammar A. Sustained prognostic implications of newly detected glucose abnormalities in patients with acute myocardial infarction: long-term follow-up of the Glucose Tolerance in Patients with Acute Myocardial Infarction cohort. Diabetes Vascular Disease Research. 2015;12(1):23-32.

25. Bartnik M, Malmberg K, Norhammar A, Tenerz A, Ohrvik J, Ryden L. Newly detected abnormal glucose tolerance: an important predictor of long-term outcome after myocardial infarction. European heart journal. 2004;25(22):1990-7.

26. Chattopadhyay S, George A, John J, Sathyapalan T. Newly diagnosed abnormal glucose tolerance determines post-MI prognosis in patients with hospital related hyperglycaemia but without known diabetes. Journal of Diabetes and its Complications 2020:107518.

27. Chattopadhyay S, George A, John J, Sathyapalan T. Adjustment of the GRACE score by 2-hour post-load glucose improves prediction of long-term major adverse cardiac events in acute coronary syndrome in patients without known diabetes. European heart journal. 2018;39(29):2740-5.

28. Chattopadhyay S, George A, John J, Sathyapalan T. Two-hour post-challenge glucose is a better predictor of adverse outcome after myocardial infarction than fasting or admission glucose in patients without diabetes. Acta diabetologica. 2018;55(5):449-58.

29. Kitazawa M, Fujihara K, Osawa T, Yamamoto M, Yamada MH, Kaneko M, Matsubayashi Y, Yamada T, Yamanaka N, Seida H. Risk of coronary artery disease according to glucose abnormality status and prior coronary artery disease in Japanese men. Metabolism. 2019;101:153991.

30. Wang H, Song Y, Tang X, Xu J, Jiang P, Jiang L, Gao Z, Chen J, Song L, Zhang Y: Impact of Unknown Diabetes and Prediabetes on Clinical Outcomes in" Nondiabetic" Chinese Patients After A Primary Coronary Intervention. Nutrition, Metabolism and Cardiovascular Diseases 2019.

31. Lenzen M, Ryden L, Öhrvik J, Bartnik M, Malmberg K, Scholte op Reimer W, Simoons ML: Diabetes known or newly detected, but not impaired glucose regulation, has a negative influence on 1-year outcome in patients with coronary artery disease: a report from the Euro Heart Survey on diabetes and the heart. European heart journal 2006, 27(24):2969-2974.

32. Otten R, Kline-Rogers E, Meier D, Dumasia R, Fang J, May N, Resin Y, Armstrong D, Saab F, Petrina M. Impact of pre-diabetic state on clinical outcomes in patients with acute coronary syndrome. Heart. 2005;91(11):1466-8.

33. Kabootari M, Hasheminia M, Azizi F, Mirbolouk M, Hadaegh F. Change in glucose intolerance status and risk of incident cardiovascular disease: Tehran Lipid and Glucose Study. Cardiovascular Diabetology. 2020;19(1):1-11.

34. Knudsen EC, Seljeflot I, Abdelnoor M, Eritsland J, Mangschau A, Müller C, Arnesen H, Andersen G. Impact of newly diagnosed abnormal glucose regulation on long-term prognosis in low risk patients with ST-elevation myocardial infarction: A follow-up study. BMC endocrine disorders. 2011;11(1):14.

\section{Figures}

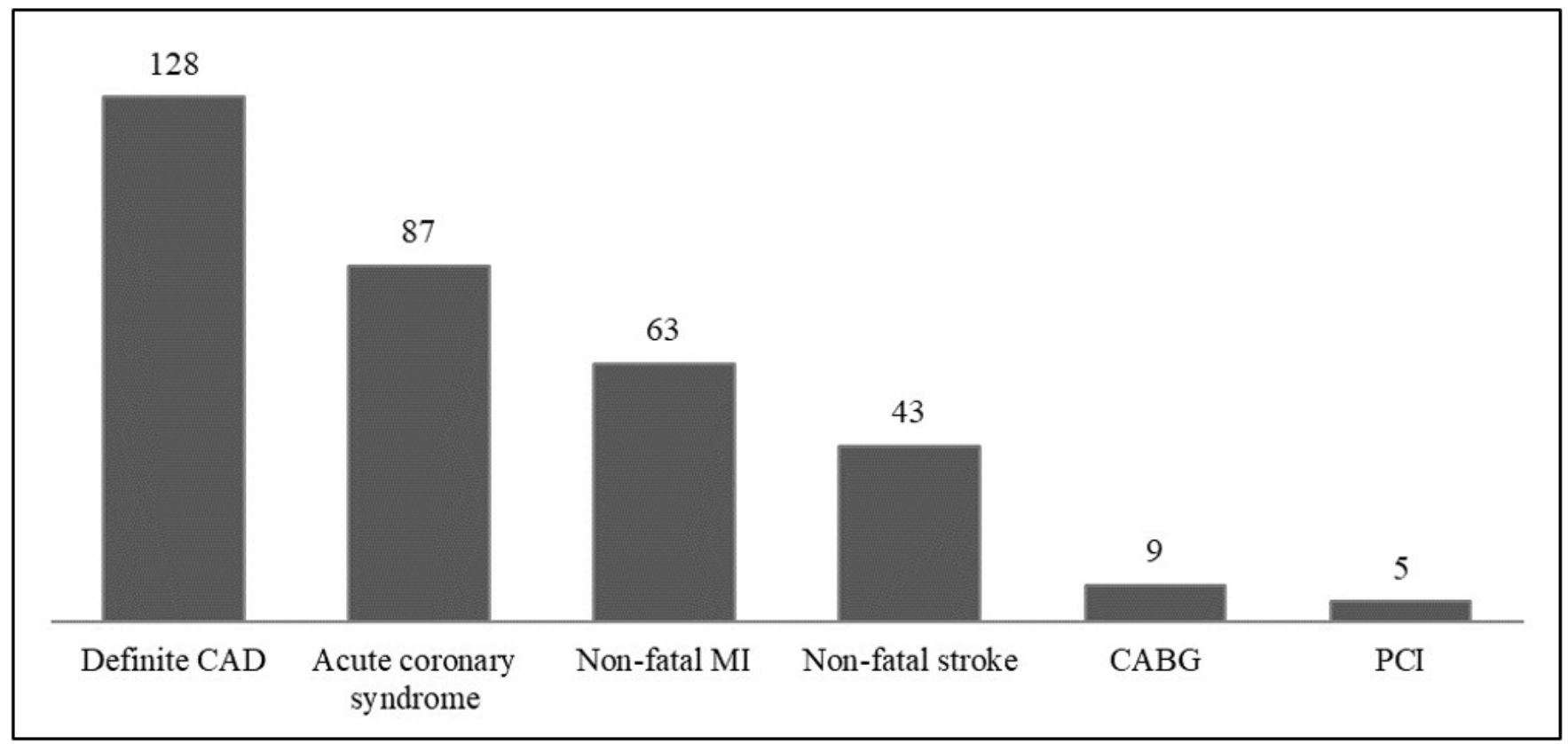

Figure 2

Details of previous events and interventions in subjects with cardiovascular disease at baseline visit. CAD, coronary artery disease; MI, myocardial infarction; CABG, coronary artery bypass graft; $\mathrm{PCl}$, percutaneous coronary intervention. 


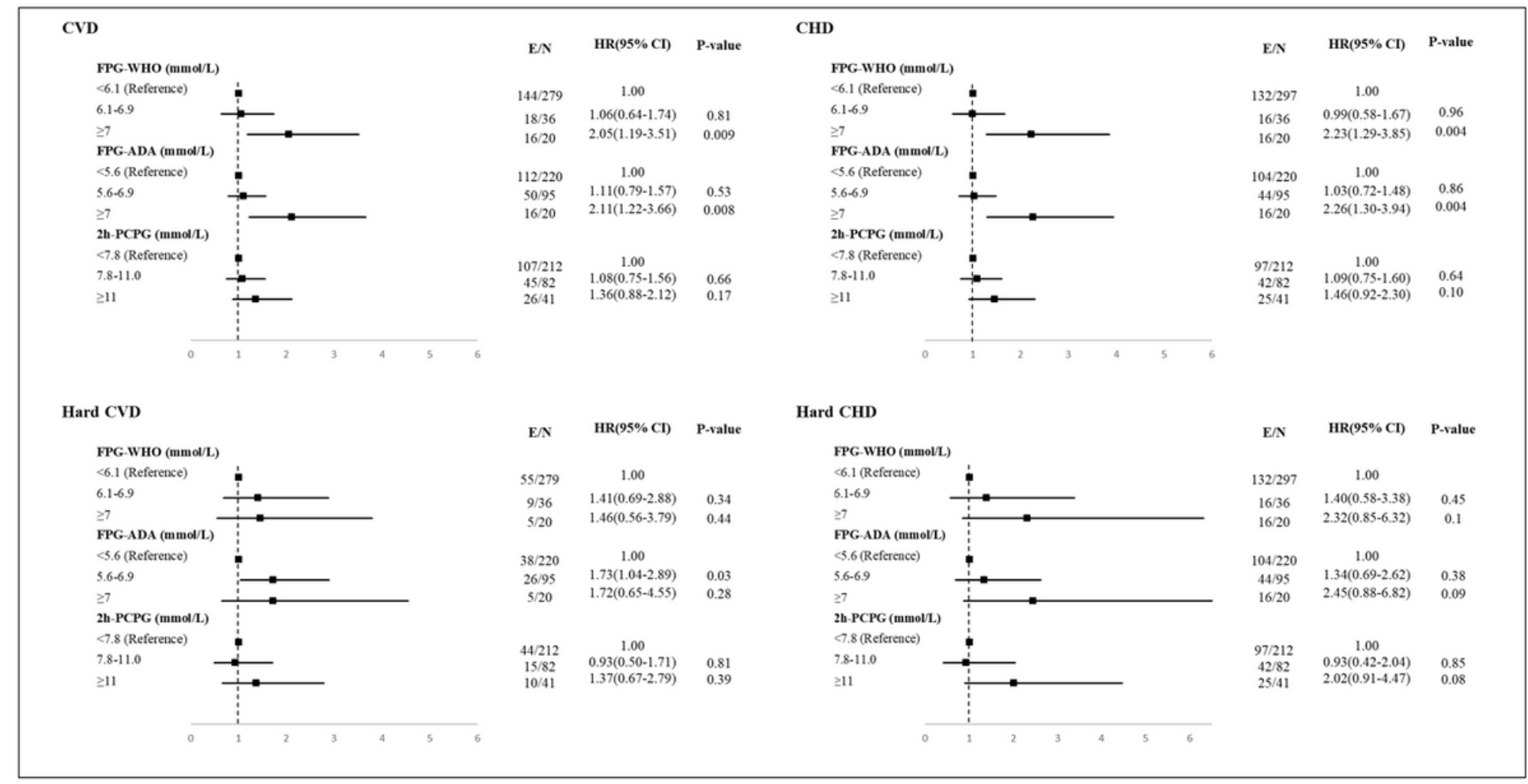

Figure 4

Multivariate adjusted hazard ratio of different glucose intolerance categories for recurrent CVD, hard CVD, CHD and hard CHD. E, event in the target group; $\mathrm{N}$, total sample size in the target group; CVD, cardiovascular disease; CHD, coronary heart disease; HR, hazard ratios; $\mathrm{Cl}$, confidence interval; FPG, fasting plasma glucose; $2 \mathrm{~h}-\mathrm{PCPG}$, 2-h post challenge plasma glucose; WHO, World Health Organization; ADA, American Diabetes Association Hard CHD events were defined as the occurrence of nonfatal MI and CHD death. Hard CVD event considered as nonfatal MI, nonfatal stroke and CVD death.

\section{Supplementary Files}

This is a list of supplementary files associated with this preprint. Click to download.

- Supplementarytables.docx

- Supplementarytables.docx

Table 4

Risks of incident diabetes based on different glucose intolerance states. $(n=270)$

\begin{tabular}{|c|c|c|c|c|c|c|}
\hline & HR & $95 \%(\mathrm{Cl})$ & $P$ value & HR & $95 \%(\mathrm{Cl})$ & $P$ value \\
\hline \multicolumn{7}{|c|}{ FPG and $2 \mathrm{~h}$-PCPG categories } \\
\hline IFG-WHO & 6.07 & $3.27-11.27$ & $<0.001$ & 4.47 & $2.36-8.47$ & $<0.001$ \\
\hline IFG-ADA & 4.55 & $2.77-7.48$ & $<0.001$ & 4.14 & $2.47-6.93$ & $<0.001$ \\
\hline IGT & 6.04 & $3.63-10.04$ & $<0.001$ & 6.10 & $3.58-10.39$ & $<0.001$ \\
\hline \multicolumn{7}{|c|}{ Per 1-SD increase } \\
\hline FPG & 2.71 & $2.08-3.54$ & $<0.001$ & 2.36 & $1.81-3.09$ & $<0.001$ \\
\hline $2 \mathrm{~h}-\mathrm{PCPG}$ & 3.11 & $2.36-4.11$ & $<0.001$ & 3.23 & $2.39-4.36$ & $<0.001$ \\
\hline \multicolumn{7}{|c|}{$\begin{array}{l}\text { HR, hazard ratios; Cl, confidence interval; IFG, impaired fasting glucose; IGT, impaired glucose tolerance; WHO, World Health Organization; ADA, American } \\
\text { Diabetes Association; FPG, fasting plasma glucose; } 2 \text { h-PCPG, 2-h post challenge plasma glucose. } \\
\text { Model 1: age and sex } \\
\text { Model 2: model } 1 \text { plus family history of diabetes, BMI, WC, hypertriglyceridemia and low HDL-C. }\end{array}$} \\
\hline
\end{tabular}

